\title{
A new operation of internal closure of the larynx for separation of the air and food passages
}

\author{
CLEMENT GRIMSHAW AND M. TESSA MORRELL \\ From the United Oxford Hospitals
}

\begin{abstract}
Indications for internal closure of the larynx are the same as those set out by Smith, Spalding, Ardran, and Livingstone (1965) for laryngectomy in non-malignant conditions. There should be no prospect of recovery from the pharyngeal palsy which endangers the life of the patient from inhalation pneumonia. The advantage of closure of the larynx over laryngectomy is that it is only a mildly traumatic procedure, being less disturbing generally and likely to avoid complications at the operation site. This simple procedure could play an important part in hastening the rehabilitation of patients with permanent pharyngeal dysphagia, allowing early removal of the tracheotomy tube. Rather than adding to the difficulties in swallowing, as a laryngectomy may do, simple closure of the larynx can increase the patient's confidence in swallowing, with early resumption of normal feeding.
\end{abstract}

Dysphagia due to paralysis or incoordinate muscle action of the pharynx constantly endangers life because of inhalation pneumonitis. Permanent protection of the airway hitherto has been by a cuffed tracheotomy tube or by a laryngectomy. Both may present difficulties in management. Another form of treatment by internal closure of the larynx is described.

\section{CASE NOTES}

The problem of dysphagia due to pharyngeal weakness was encountered in an 82-year-old man suffering from severe pulmonary infection and in heart failure.

A benign stricture of the lower third of the oesophagus was intubated with a Celestin tube in April 1965, which allowed liquids and soft solids to be swallowed fairly satisfactorily. In November 1965 the patient was readmitted with renewed difficulty in swallowing and intermittent inhalation of food.

Oesophagoscopy revealed no Celestin tube in the oesophagus, and the tube was removed from the stomach, an annular stricture above the cardia being dilated digitally through the gastrotomy incision. Intermittent inhalation of pharyngeal contents continued, however, and a few days later a tracheotomy with a cuffed tube was made. The difficulty in swallowing was seen to lie in the pharynx and preceded the tracheotomy. The cause was considered probably to be a vertebro-basilar ischaemia (Dr. J. K. Spalding). A bilateral pharyngeal myotomy was made under local anaesthesia by Mr. Bernard Coleman. Though this brought some improvement in swallowing, food still continued to enter the larynx.
As it was clear that the patient could not leave hospital so long as he retained the tracheotomy tube, it was desirable to interrupt the continuity between the air and food passages. A decision to close the larynx by laryngo-fissure in preference to performing a laryngectomy was conceived in the expectation that this would be a relatively minor procedure in a feeble patient and would avoid possible infection of a more extensive wound in the presence of continuing pulmonary infection and a tracheotomy stoma.

The Operation (Figure) Under general anaesthesia (Professor Crampton Smith) a midline incision was made from the level of the hyoid bone to the cricoid cartilage and the larynx was exposed by separating the strap muscles. The thyroid cartilage with the underlying mucosa was divided in the midline and each side was retracted laterally. A transverse circumferential incision was then made immediately above the vocal fold through the mucosa and underlying muscles as one layer, which was raised from the medial aspect of the thyroid lamina both cranially and caudally on each side. The crico-arytenoid joints were disarticulated. The circumferential incision was at the 'watershed' of the arterial and the nerve supply to the larynx from above and below, and therefore in a most suitable position for maintaining good nutrition of the mobilized tissues.

By approximating the vestibular folds and the vocal cords separately with a few fine interrupted silk sutures, a double diaphragmatic internal closure of the larynx was made. The thyroid laminae were reapposed by fine sutures including the overlying fascia and perichondrium, and the skin was closed. The wound healed normally and the patient's 

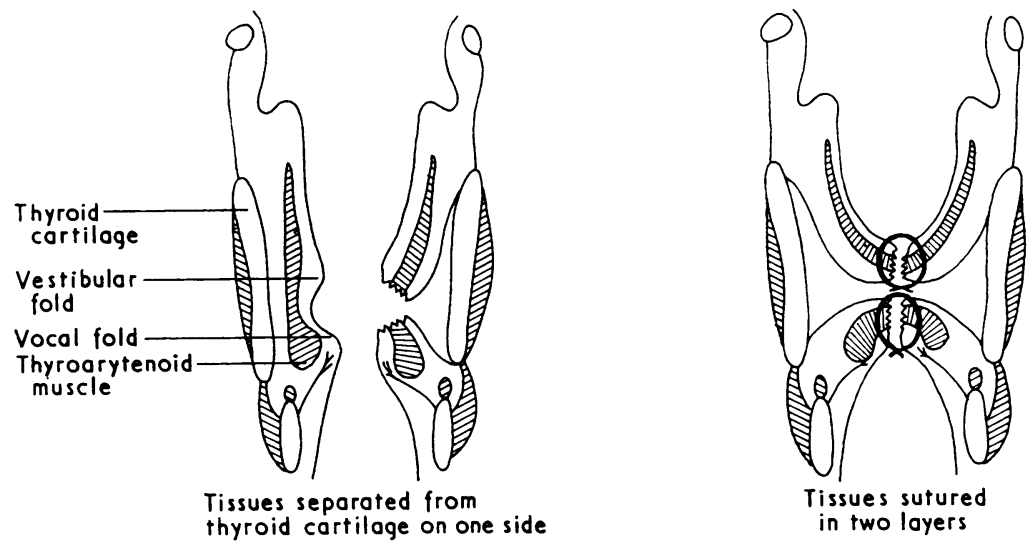

PIGURE. Coronal section through larynx.

tracheotomy tube was removed 10 days later when a barium swallow had demonstrated the effective closure of the larynx, a shallow pool lying in the aditus when the patient was in the erect position.

Consideration was given to closing the entrance of the larynx by mobilizing the epiglottis and suturing it to the margins of the aditus, and this was done preliminary to the laryngo-fissure. As was anticipated might be the case, these sutures cut out, the epiglottis returning to its normal position 10 days later. It is not thought that this is likely to be a useful part of this procedure.

\section{REFERENCE}

Smith, A. C., Spalding, J. M. K., Ardran, G. M., and Livingstonc. G, (1965). Laryngectomy in the management of severe dysphagia in non-malignant eonditions. Lancet, 2, 1094. 